\title{
Multiparametric Analysis of Sniff Nasal Inspiratory Pressure Test in Middle Stage Amyotrophic Lateral Sclerosis
}

\author{
Antonio Sarmento ${ }^{1}$, Andrea Aliverti², Layana Marques ${ }^{1}$, Francesca Pennati², \\ Mario Emílio Dourado-Júnior ${ }^{3}$, Guilherme Fregonezi ${ }^{1}$ and Vanessa Resqueti ${ }^{1 *}$
}

\begin{abstract}
'PneumoCardioVascular Laboratory, Hospital Universitário Onofre Lopes, Empresa Brasileira de Serviços Hospitalares (EBSERH), Departamento de Fisioterapia, Universidade Federal do Rio Grande do Norte, Natal, Brazil, ${ }^{2}$ Dipartimento di Elettronica, Informazione e Bioingegneria, Politecnico di Milano, Milan, Italy, ${ }^{3}$ Ambulatório de Neurologia, Empresa Brasileira de Serviços Hospitalares (EBSERH), Departamento de Medicina Integrada, Universidade Federal do Rio Grande do Norte, Natal, Brazil
\end{abstract}

OPEN ACCESS

Edited by:

Angelo Schenone,

Università di Genova, Italy

Reviewed by:

Claudia Caponnetto,

Azienda Ospedaliera

Universitaria San Martino

(IRCCS), Italy

Andrea Calvo,

Università degli Studi

di Torino, Italy

*Correspondence:

Vanessa Resqueti

vanessaresqueti@hotmail.com

Specialty section:

This article was submitted to

Neuromuscular Diseases,

a section of the journal

Frontiers in Neurology

Received: 07 February 2018

Accepted: 18 April 2018

Published: 02 May 2018

Citation:

Sarmento A, Aliverti A, Marques L, Pennati F, Dourado-Júnior ME, Fregonezi G and Resqueti V (2018) Multiparametric Analysis of Sniff

Nasal Inspiratory Pressure

Test in Middle Stage Amyotrophic Lateral Sclerosis.

Front. Neurol. 9:306.

doi: 10.3389/fneur.2018.00306
The relaxation rates and contractile properties of inspiratory muscles are altered with inspiratory muscle weakness and fatigue. This fact plays an important role in neuromuscular disorders patients and had never been extensively studied in amyotrophic lateral sclerosis (ALS). In this cross-sectional study, these parameters were investigated non-invasively through nasal inspiratory sniff pressure test (SNIP) in 39 middle stage spinal onset ALS subjects and compared with 39 healthy controls. ALS patients were also divided into three subgroups according to a decline in their percentage of predicted forced vital capacity (FVC\%pred) as well as a decline in the ALS functional rating scale score and its respiratory subscore (R-subscore) in order to determine the best parameter linked to early respiratory muscle weakness. When compared with healthy subjects, middle stage ALS subjects exhibited a significantly lower $(p<0.0001)$ maximum relaxation rate and maximum rate of pressure development (MRPD), as well as a significantly higher $(\rho<0.0001)$ tau $(\tau)$, contraction time, and half-relaxation time. The results from receiver operating characteristic curves showed that MRPD (AUC $0.735, p<0.001$ ) and $\mathrm{FVC}_{\% \text { pred }}$ (AUC 0.749, $p=0.009$ ) were the best discriminator parameters between ALS patients with $\leq 30$ and $>30$ points in the ALS functional rating scale. In addition, 1/2RT (AUC 0.720, $p=0.01$ ), FVC\%pred (AUC 0.700, $p=0.03$ ), $\tau$ (AUC 0.824, $p<0.0001$ ), and MRPD (AUC 0.721, $p=0.01$ ) were the parameters more sensitive in detecting a fall of three points in the R-subscore. On the other hand, MRPD (AUC 0.781, $p<0.001$ ), $\tau$ (AUC 0.794, $p=0.0001$ ), and percentage of predicted of SNIP (AUC 0.769, $p=0.002$ ) were the parameters able to detect a fall in $30 \%$ of the $\mathrm{FVC}_{\%}$ pred in middle stage ALS patients. The contractile properties and relaxation rates of the diaphragm are altered in middle stage spinal onset ALS when compared with healthy subjects. These parameters are able to discriminate between those middle stage ALS subjects with early decline in inspiratory muscle function and those who not.

Keywords: amyotrophic lateral sclerosis, forced vital capacity, inspiratory muscle weakness, relaxation rates, respiratory subscore, sniff nasal inspiratory pressure 


\section{INTRODUCTION}

Amyotrophic lateral sclerosis (ALS) is a rare neurodegenerative disorder characterized by progressive weakness of the skeletal and respiratory muscle (1). The median survival from first symptoms ranges from 2 to 4 years (2), and although respiratory insufficiency can be present in approximately $3 \%$ of patients $(3,4)$, it frequently emerges in the late phase of the disease representing the most frequent cause of death (1).

Global assessment scores, such as the ALS functional rating scale (5) (ALSFRS-R), is a useful and valid parameter in predicting survival in this population $(6,7)$ and has proved to be related to forced vital capacity (8) (FVC). Since respiratory function and muscle strength are of clinical importance and represent crucial factors influencing survival in ALS $(9,10)$, the monitoring of these parameters is essential during disease progression. The gold standard measurement of respiratory muscle strength involves the insertion of esophageal and/or gastric balloon catheters through the nose (11). However, the sniff nasal inspiratory pressure (SNIP) has been proposed as a non-invasive alternative method and proved to accurately reflect diaphragm strength (12) and global inspiratory muscle strength (13).

In ALS patients, the already weakened respiratory muscles are easily suitable to fatigue (14) and this fact may play an important role in the development of ventilatory failure (15). It has been demonstrated that the relaxation rate of inspiratory muscles is altered by the development of inspiratory muscle fatigue $(16,17)$ and that relaxation rates obtained from a maximal sniff accurately reflect those obtained from esophageal pressure $(16,18)$. Relaxation rates can be described in terms of maximum relaxation rate (MRR), half-relaxation time (1/2RT), and time constant of the pressure decay curve $(\tau$, tau) after voluntary contraction of a muscle (16). Furthermore, the contractile properties of the diaphragm [namely, maximum rate of pressure development (MRPD) and contraction time (CT)] are also altered in fatigue and have been used as an index of the motor output of the respiratory center (19) as well as to assess inspiratory muscle function $(11,20,21)$.

Apart from fatigue in healthy subjects $(16-18,22-24)$, physiological and/or disease-related changes in diaphragm relaxation have not been extensively investigated in ALS patients through the SNIP test. The present work aimed to non-invasively measure the relaxation rates and the contractile properties of the inspiratory muscles in ALS patients through SNIP test (1) in comparison to healthy subjects and (2) in relation to early respiratory symptoms in order to determine the best parameter linked to early respiratory muscle weakness. We hypothesized that these parameters are altered in ALS patients and can be indicators of inspiratory muscle weakness.

\section{MATERIALS AND METHODS}

\section{Subjects}

This cross-sectional study was conducted according to the World Medical Association Declaration of Helsinki and approved by the Research Ethics Committee under number 1.344.512/2015.
All individuals involved in the study signed an informed consent form.

We investigated 39 subjects with ALS (22 males), recruited from the Hospital Universirátio Onofre Lopes and diagnosed by a neurologist according to the El Escorial criteria (25) as "Probable or definite," and 39 healthy controls (19 males). ALS subjects with cardiovascular, pulmonary, or other neurological diseases, as well as with bulbar dysfunction signs or tracheostomy were not included. Those who failed to perform the assessments or refuse to participate in the study were excluded.

Control group included self-reported age-matched healthy subjects with no history of cardiovascular, neurological or pulmonary diseases. Those with FVC and $\mathrm{FEV}_{1}<80 \%$ of predicted were excluded.

\section{Spirometry}

Spirometry was performed using a Koko Digidoser spirometer (nSpire Health, Longmont, CO, USA) and carried out with the subjects positioned sitting on a chair with feet supported and trunk flexion of $90^{\circ}$ according to the ATS/ERS guidelines (11). All values obtained were compared with absolute and percentage of predicted values for the Brazilian population (26).

\section{Respiratory Muscle Strength}

Maximum inspiratory and expiratory pressures [maximum inspiratory pressure (MIP) and maximum expiratory pressure (MEP), respectively] and SNIP were measured using a digital manometer (NEPEB-Labcare, Belo Horizonte) with the subjects seated on a chair. MIP was measured starting from residual volume and MEP from total lung capacity, while SNIP was performed starting from functional residual capacity (FRC) (27). Data obtained were compared with previous reference values (28, 29 ), and the highest value of each test was considered for analysis.

\section{SNIP Curve Analysis}

All subjects were asked to perform a short, sharp inspiratory effort through the nostrils with lips closed. Since some sniff parameters can be affected by changes in muscle length and the activity of expiratory muscles could interfere in the analysis, the sniff maneuvers were performed from FRC and a passive relaxation right after reaching the peak of pressure was requested $(23,30)$. At least 10 maximal sniffs, with an interval of about $30 \mathrm{~s}$ in between, were performed by all subjects. The following criteria were used to select those sniffs suitable for analysis: (1) sniff performed from FRC; (2) peak pressure maintained for less than $50 \mathrm{~ms}$; (3) duration of the inspiratory effort less than $500 \mathrm{~ms}$; and (4) sniff pressure waveform with smooth decay curve $(16,31)$.

Figure 1 shows the parameters derived from the SNIP test. From the sniff maneuver trace, CT and 1/2RT were calculated as the time to reach the peak pressure of the sniff and the halftime of the relaxation curve, respectively (32). MRPD, expressed as $\mathrm{cmH}_{2} \mathrm{O} \cdot \mathrm{ms}^{-1}$, was calculated as the negative peak of the first derivative of pressure-time curve $(21,33)$ while MRR, expressed as milliseconds ${ }^{-1}$, was defined as the positive peak of the first derivative of pressure-time curve normalized to the sniff peak pressure, in order to make contractions of different intensities comparable (18). 

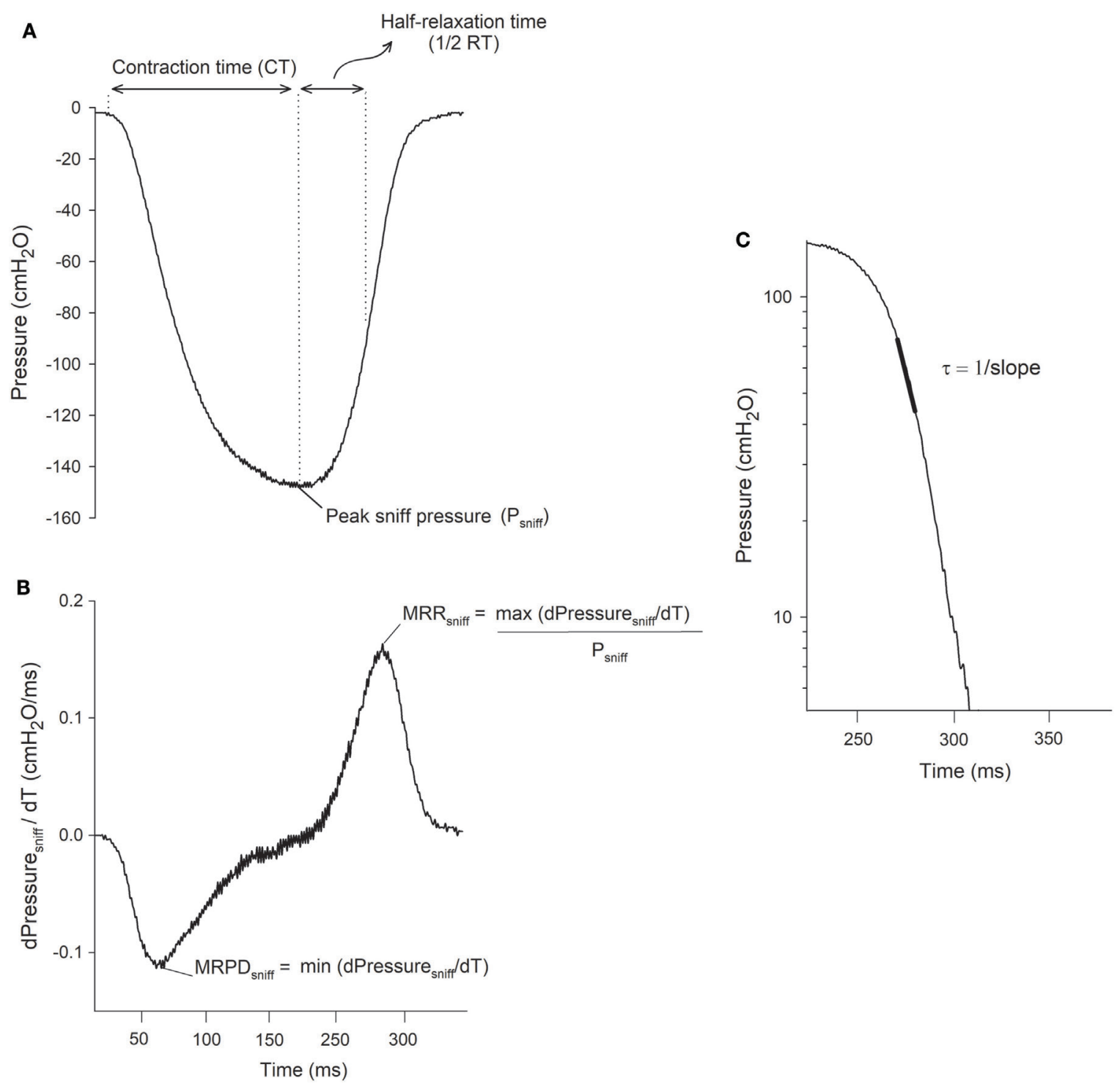

FIGURE 1 | Representative tracings of the sniff nasal inspiratory pressure (SNIP) test and its parameters. (A) Tracings of SNIP change; peak sniff pressure ( $\mathrm{P}_{\text {sniff }}$;

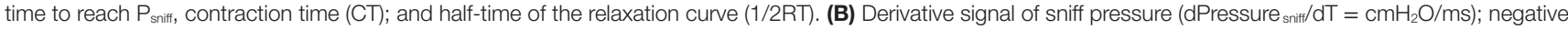
peak $\mathrm{dP}_{\text {sniff }} / \mathrm{dT}$, maximum rate of pressure development (MRPD) positive peak $\mathrm{dP}_{\text {sniff }} / \mathrm{dT}$ normalized by $\mathrm{P}_{\text {sniff, }}$ maximum relaxation rate (MRR). (C) Decay portion of the sniff pressure plotted on semilog scale vs. time (ms). Linear black portion indicates a single exponential function with a time constant, $\tau=1 /$ slope. $\mathrm{cmH}_{2} \mathrm{O}$, centimeters of water.

The time constant $(\tau)$, was also calculated. When the natural logarithm of pressure is plotted as a function of time, the lower $50-70 \%$ of the pressure decay follows a straight line $(18,34)$ (Figure 1C), indicating that the pressure follows a monoexponential decay with a time constant $\tau$ ( $\tau=1$ /slope). For the measurement of $\tau$ to be accepted, the correlation coefficient of the individual regression line (ln P vs. time) had to be $\geq 0.96$ (35).

Sniff nasal inspiratory pressure curve analysis was performed by custom software developed in MATLAB (The MathWorksInc, Natick, MA, USA).

\section{Functionality and Stage of the Disease}

Functionality was measured using the ALSFRS-R (maximum 48 points), validated for the Brazilian population (5), as well as its respiratory subscore (R-subscore) alone (36) (maximum 12 points). In addition, the stage of the disease was determined according to disease progression proposed by Roche et al. (37).

\section{Statistical Analysis}

To statistical analysis, data from ALS subjects were divided into three subgroups, defined by the degree of decline of the (1) respiratory function $(2,38,39)\left(\leq 70\right.$ and $>70$ of $\left.F V C_{\% \text { pred }}\right)$,

(2) ALSFRS-R total score ( $\leq 30$ and $>30$ points), and

(3) R-subscore ( $\leq 9$ and $>9$ points) $(40,41)$.

Data are expressed as median [25-75th percentile] unless otherwise stated. Normality and distribution of data were performed using Shapiro-Wilk test. Data between ALS and healthy subjects (intergroup analysis) were studied using the unpaired 
$t$-test or Mann-Whitney test for parametric and non-parametric data, respectively. One-way ANOVA or Kruskal-Wallis test was applied to compare subgroup with control group data and, in the event of statistical significance; Bonferroni's or Dunn's post hoc test was applied, respectively, to identify differences between groups.

To avoid type II error, the power of the study was calculated as well as effect sizes for all data. For parametric data, effect sizes were calculated using Cohen's $d$ for intergroup analysis and Cohen's $f$ for subgroup analysis (42). For non-parametric data, Cohen's $d$ was calculated for intergroup analysis according to Fritz et al. (43) and $\varepsilon^{2}$ for subgroup analysis according to Tomczak and Tomczak (44) (see Supplementary Material).

Receiver operating characteristic (ROC) curves were calculated for SNIP parameters between middle stage ALS and healthy subjects, as well as between subgroups. The area under the curve (AUC) and its 95\% confidence interval were calculated. Optimal cutoff point and its $95 \%$ confidence interval were also calculated for each parameter according to the Youden index (45).

Inferential data analysis was performed using GraphPad Prism ${ }^{\circledR}$ software version 6.01 . The power of the study and effect sizes were analyzed using $\mathrm{G}^{\star}$ Power software, version 3.1.9.2 (Kiel, Germany), and ROC curves were analyzed using MedCalc (Ostend, Belgium) version 14.8.1. For all statistical analysis, a $p$-value of $<0.05$ (two-sided) was considered as statistically significant.

\section{RESULTS}

Data related to diagnosis criteria, region of onset, clinical phenotype as well as the presence of familial ALS and cognitive impairment of all ALS included in the study are shown in Table S1 in Supplementary Material. Anthropometric, spirometric, respiratory muscle strength, and functionality data are shown in Table 1. ALS subjects were characterized by significant lower spirometric and respiratory muscle strength values. All ALS subjects were classified as middle stage. The mean ALSFRS-R score was $32.5 \pm 8.8(67.7 \pm 18.3 \%)$, and the mean R-subscore was $10 \pm 2(83.3 \pm 16.6)($ see Table S2 in Supplementary Material).

All parameters extracted from the sniff curve were significantly different between ALS and healthy subjects. A significantly lower MRR $(p<0.0001$, Cohen's $d=0.44)$ and MRPD ( $p<0.0001$, Cohen's $d=0.71$ ) were found in ALS subjects, as well as a higher CT $(p<0.0001$, Cohen's $d=1.21), 1 / 2 \mathrm{RT}$ $(p<0.001$, Cohen's $d=0.42)$, and $\tau(p<0.0001$, Cohen's $d=0.64)$ (Figure 2).

A post hoc analysis considering a $p$-value of $<0.01$ and the calculated effect size for $\tau$ between ALS and healthy subjects (Cohen's $d=0.64$ ) showed a statistical power $(1-\beta)=0.99$ for this study.

\section{ALSFRS-R, R-Subscore, and FVC \%pred Subgroups}

As shown in Table 2, all subgroups of ALS subjects presented a lower $\mathrm{FVC}_{\% \text { pred, }}$ SNIP\%pred, MRR, and MRPD and higher CT, 1/2RT, and $\tau$ when compared with healthy subjects. However, subjects
TABLE 1 | Characteristics of the subjects in relation to anthropometric data, absolute and predicted values of lung function, respiratory muscle strength, and functional capacity.

\begin{tabular}{|c|c|c|c|}
\hline & Healthy & ALS & $p$ \\
\hline Subjects (n) & 39 & 39 & - \\
\hline Age (years) & $47.9 \pm 11.1$ & $52.9 \pm 12.5$ & 0.111 \\
\hline Height (ms) & $1.63 \pm 0.1$ & $1.65 \pm 0.1$ & 0.500 \\
\hline Weight (kg) & $69.6 \pm 11$ & $65 \pm 13$ & 0.100 \\
\hline BMI $\left(\mathrm{kg} / \mathrm{m}^{2}\right)$ & $26.2 \pm 5.6$ & $23.9 \pm 5.7$ & 0.07 \\
\hline FVC (L) & $3.79 \pm 0.8$ & $2.49 \pm 1.06$ & $<0.0001$ \\
\hline FVC\%pred & $98.8 \pm 10.7$ & $63.1 \pm 23.1$ & $<0.0001$ \\
\hline $\mathrm{FEV}_{1}(\mathrm{~L})$ & $3.10 \pm 0.68$ & $1.87 \pm 0.83$ & $<0.0001$ \\
\hline $\mathrm{FEV}_{1 \% \text { pred }}$ & $98.8 \pm 10.4$ & $58.5 \pm 21.9$ & $<0.0001$ \\
\hline $\mathrm{FVC} / \mathrm{FEV}_{1}$ & $0.81 \pm 0.04$ & $0.76 \pm 0.12$ & 0.008 \\
\hline FVC/FEV $1 \%$ pred & $100.1 \pm 4.4$ & $94.3 \pm 15.6$ & 0.02 \\
\hline $\mathrm{FEF}_{25-75 \%}$ & $3.29 \pm 0.87$ & $1.86 \pm 1.05$ & $<0.0001$ \\
\hline $\mathrm{PEF}(\mathrm{L} / \mathrm{s})$ & $6.41 \pm 1.91$ & $3.32 \pm 2.19$ & $<0.0001$ \\
\hline $\mathrm{SNIP}\left(\mathrm{cmH}_{2} \mathrm{O}\right)$ & $103.3 \pm 29.4$ & $48.36 \pm 27.04$ & $<0.0001$ \\
\hline SNIP\%pred & $100.4 \pm 24$ & $47.2 \pm 24.7$ & $<0.0001$ \\
\hline $\operatorname{MIP}\left(\mathrm{cmH}_{2} \mathrm{O}\right)$ & $105 \pm 27.45$ & $48.1 \pm 22.50$ & $<0.0001$ \\
\hline $\mathrm{MIP}_{\% \text { pred }}$ & $103.3 \pm 20.9$ & $48.4 \pm 22.7$ & $<0.0001$ \\
\hline $\mathrm{MEP}\left(\mathrm{cmH}_{2} \mathrm{O}\right)$ & $125.4 \pm 36.46$ & $58.46 \pm 31.92$ & $<0.0001$ \\
\hline MEP\%pred & $121.8 \pm 31.9$ & $56.6 \pm 32.1$ & $<0.0001$ \\
\hline ALSFRS-R & - & $32.5 \pm 8.8$ & - \\
\hline Respiratory subscore & - & $10 \pm 2$ & - \\
\hline
\end{tabular}

Data presented as mean $\pm S D$.

FVC, forced vital capacity; FEV $V_{1}$, forced expiratory volume in the first second; FEV FVC, ratio of forced expiratory volume in the first second to forced vital capacity; $F E F_{25-75 \%}$, forced expiratory flow at 25-75\%; PEF, peak expiratory flow; MIP, maximum inspiratory pressure; MEP, maximum expiratory pressure; SNIP, sniff nasal inspiratory pressure; ALSFRS-R, amyotrophic lateral sclerosis functional rating scale-revised; \%pred, percentage of predicted; $\mathrm{CmH}_{2} \mathrm{O}$, centimeters of water.

with functional capacity $\leq 30$ (13 subjects) exhibited significantly lower values of $\mathrm{FVC}_{\% \text { pred }}$ when compared to ALS subjects with $>30$ points; and those with $\leq 9$ (14 subjects) presented a significantly lower $\mathrm{FVC}_{\% \text { pred }}$ as well as higher 1/2RT and $\tau$ values when compared to those with $>9$ points. On the other hand, when ALS subjects were classified according to $\mathrm{FVC}_{\% \text { pred, }}$, those with $<70 \%$ exhibited significantly higher $\tau$ and lower SNIP $_{\% \text { pred }}$ values when compared to ALS with values $>70 \%$.

\section{ROC Analysis}

Since SNIP $\%$ pred is one of the respiratory prognostic markers mostly considered in ALS $(38,46)$, this parameter was also included in the ROC analysis. As shown in Table 3, all sniff parameters were significantly able to discriminate between ALS and healthy. Of these, MRPD was the parameter with the highest AUC. When dividing the ALS subjects between those with ALSFRS-R score $\leq 30$ and $>30$, only the MRPD and FVC\%pred were statistically significant (Table 4). However, when taking into account the subdivision between those ALS with R-subscore $\leq 9$ and $>9$ points, MRPD, $1 / 2 \mathrm{RT}$, $\tau$, and $\mathrm{FVC}_{\% \text { pred }}$ showed to be statistically significant (Table 5). On the other hand, MRPD, $\tau$, and SNIP ${ }_{\% \text { pred }}$ parameters were statistically significant when subjects were classified according to $\mathrm{FVC}_{\% \text { pred }}$ classification (Table 6; Figure 3).

\section{DISCUSSION}

The main findings of this study are that (1) the sniff test provides parameters, apart from its peak pressure, able to discriminate 

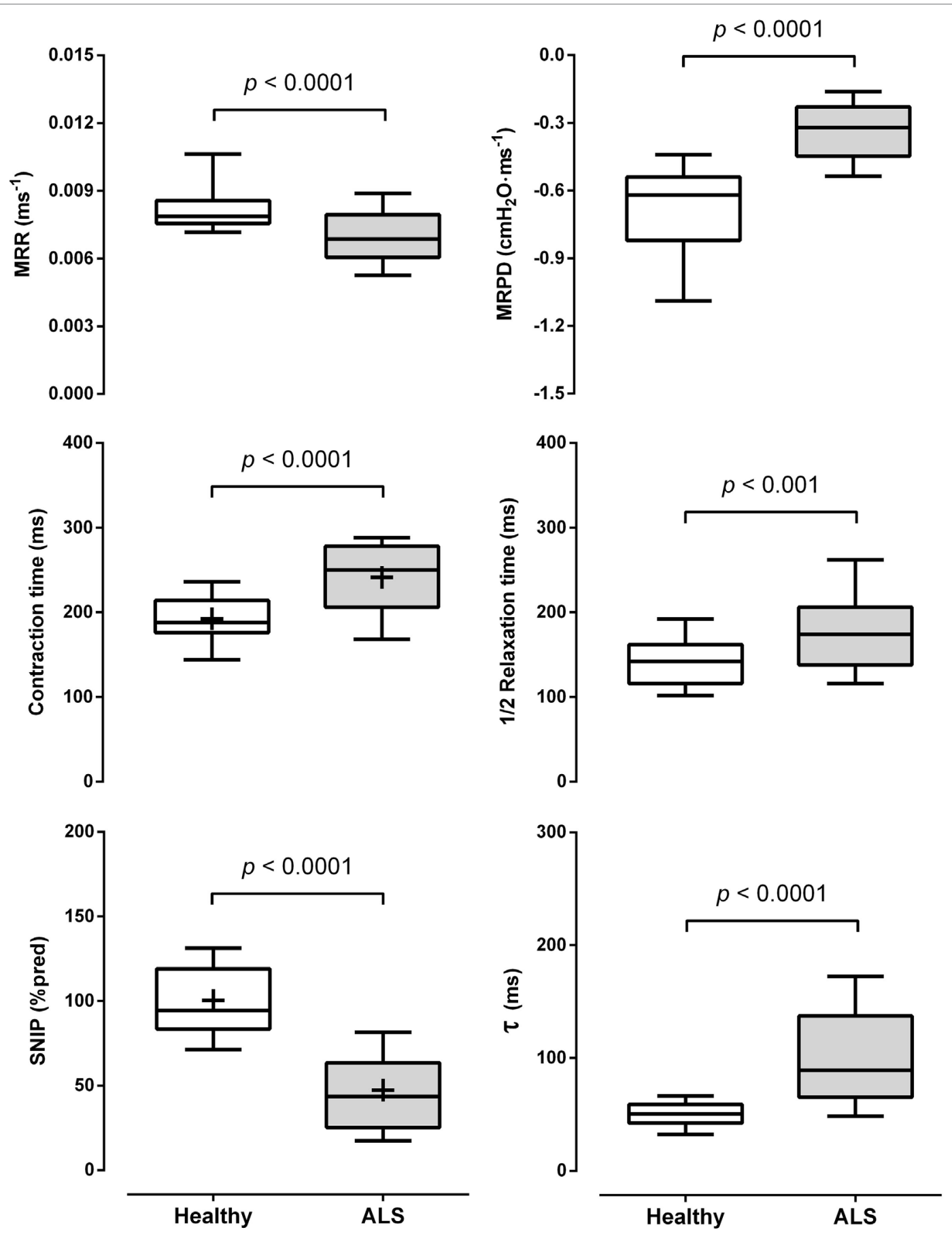

FIGURE 2 | Data are shown as median [25-75th percentile]. Comparisons between the parameters obtained from the sniff nasal inspiratory pressure (SNIP) curve [maximum relaxation rate (MRR), maximum rate of pressure development (MRPD), contraction time, half-relaxation time (1/2RT), and tau ( $\tau)$ ] and percentage of predicted of the SNIP test (SNIP\%pred) between amyotrophic lateral sclerosis (ALS) and healthy subjects. $\mathrm{cmH}_{2} \mathrm{O}$ : centimeters of water; + , mean for parametric analysis.

between healthy and middle stage ALS subjects, and that (2) some of these parameters, namely $\tau$, MRPD, and $1 / 2 \mathrm{RT}$, are more sensitive in detecting impaired inspiratory muscle function in ALS than the peak pressure itself.

According to Kyroussis et al. (22), measurements of relaxation rates obtained from nasal sniffs accurately reflects those from esophageal pressure curves and can be used as an index of the onset and recovery of respiratory muscle fatigue. Moreover, measurements of nasal sniffs are simple, tolerated, and minimally invasive and can provide a quantitative response index to fatigue and therapeutic interventions in neuromuscular disease patients $(47,48)$. In our study, all parameters derived from the 


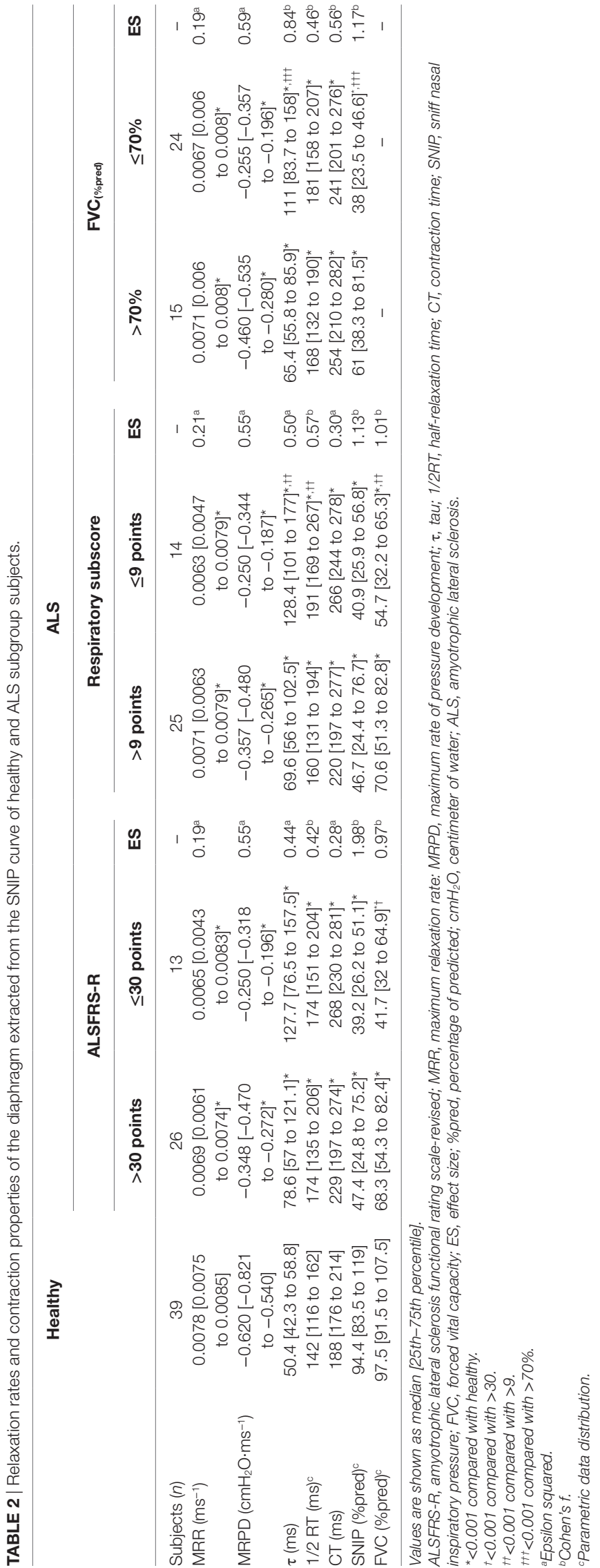

SNIP curve were significantly different between middle stage ALS and healthy subjects, being in agreement with two previous studies performed in subjects with neuromuscular disorders $(47,49)$. Evangelista et al. (49), observed that a reduced MRR was reliable in identifying the delayed relaxation of the respiratory muscles in myotonic dystrophy type 1 patients when compared to healthy controls; while Garcia-Rio et al. (47), despite heterogeneity of the study population, found that the decreased MRR of neuromuscular disease patients was accompanied by the deterioration in the functional reserve of the diaphragm as well as of the inspiratory muscles.

The rationale for measuring relaxation rates from pressure curves is based on the assumption that the decay portion of the curve, when expiration is totally passive, corresponds to the relaxation phase of inspiratory muscle contraction (18). The decrease in MRR and increase in $\tau$ are adaptive mechanisms and had been shown to be an early sign of the onset of fatigue $(17,50)$. The alterations of these parameters occur before the decrease in peak diaphragmatic pressure $(17,31,47)$. When respiratory muscles do develop fatigue the peak pressure decreases linearly with the slowing of the MRR and exponentially with the increase of $\tau$ due to common or concomitant metabolic changes of the muscle fiber $(17,34,51)$. In addition, the loss of muscular force during fatigue makes the muscle contractile speed to decrease resulting in an increase in $\mathrm{CT}$ and prolongation of relaxation time as an adaptive mechanism $(52,53)$ which is also related to intracellular and metabolic factors (i.e., the decline of the calcium uptake from the sarcoplasmic reticulum, depletion of ATP, and intracellular acidosis) $(48,54)$.

To our knowledge, apart from various studies about the relaxation rate in healthy adults $(21,23,33)$ and different diseases [COPD (51), cystic fibrosis $(55,56)$, and intubated patients weaning from mechanical ventilation (31)], the literature is scarce about the measurements of MRPD, $\tau$, CT, and 1/2RT in neuromuscular disease patients precluding the possibility of comparing our data to data derived from a similar population. Our results showed a decreased MRPD in middle stage ALS when compared to healthy subjects and, as it is derived from the initial incline of the SNIP curve and reflects respiratory muscle function (11) as well as respiratory motor output (19), we believe that this parameter is linked to the decreased capacity of the diaphragm to generate force and expand the lungs (39). Furthermore, as the already weakened respiratory muscles of patients with ALS are easily fatigable (14), the results found about the contractile properties (CT and MRPD) and dynamics of relaxation (MRR, $\tau$, and $1 / 2 \mathrm{RT})$ of the diaphragm $(11,16)$ indicates a high respiratory muscle load and reinforces the hypothesis that the middle stage ALS subjects were presumably at risk of developing respiratory muscle fatigue $(14,18,21,33,56)$.

The ALSFRS- $\mathrm{R}$ is a simple and reliable scale that predicts survival and can be used as the only functional outcome measure in early phase trials (40), while its R-subscore was designed to assess indirectly the respiratory function (36) being also sensitive in detecting early respiratory symptoms of ventilatory insufficiency (57-59). Castrillo-Viguera et al. (41) suggested that a percentage change of at least $20-25 \%$ in the slope of decline of the ALSFRS-R scale would represent a clinically meaningful 
TABLE 3 | Receiver operating characteristic analysis between healthy and ALS subjects.

\begin{tabular}{|c|c|c|c|c|c|}
\hline \multicolumn{6}{|c|}{ Healthy and ALS } \\
\hline & AUC $(95 \% \mathrm{Cl})$ & Optimal cutoff $(95 \% \mathrm{Cl})$ & Sensitivity (\%) & Specificity (\%) & $p$ \\
\hline $\operatorname{MRR}\left(\mathrm{ms}^{-1}\right)$ & 0.755 (0.645 to 0.845$)$ & 0.0073 (0.0068 to 0.0073) & 66.67 & 89.74 & $<0.0001$ \\
\hline $\operatorname{MRPD}\left(\mathrm{cmH}_{2} \mathrm{O} \mathrm{ms}^{-1}\right)$ & 0.916 (0.830 to 0.967$)$ & $-0.420(-0.540$ to $-0.398 .5)$ & 74.36 & 97.44 & $<0.0001$ \\
\hline$\tau(\mathrm{ms})$ & 0.874 (0.779 to 0.938) & $66(53.7$ to 79.8$)$ & 74.36 & 89.74 & $<0.0001$ \\
\hline 1/2 RT (ms) & 0.743 (0.631 to 0.835$)$ & 154 (120.9 to 164$)$ & 71.79 & 71.79 & $<0.0001$ \\
\hline $\mathrm{CT}(\mathrm{ms})$ & 0.795 (0.688 to 0.878$)$ & 215 (202 to 262) & 69.23 & 82.05 & $<0.0001$ \\
\hline SNIP (\%pred) & 0.936 (0.856 to 0.979$)$ & 81.5 (73.7 to 81.5$)$ & 92.31 & 84.62 & $<0.0001$ \\
\hline FVC (\%pred) & 0.911 (0.825 to 0.964) & 81.1 (67.9 to 83.7) & 79.49 & 97.44 & $<0.0001$ \\
\hline
\end{tabular}

AUC, area under curve; $C l$, confidence interval; MRR, maximum relaxation rate; MRPD, maximum rate of pressure development; $\tau$, tau; $1 / 2 R T$, half-relaxation time; CT, contraction time; SNIP, sniff nasal inspiratory pressure; FVC, forced vital capacity; ES, effect size; \%pred, percentage of predicted; $\mathrm{CmH}_{2} \mathrm{O}$, centimeter of water; ALS, amyotrophic lateral sclerosis.

TABLE 4 | Receiver operating characteristic analysis between ALS subjects classified according to a decrease in the ALSFRS-R scale score.

ALS-ALSFRS-R

\begin{tabular}{|c|c|c|c|c|c|}
\hline & AUC $(95 \% \mathrm{Cl})$ & Optimal cutoff (95\% Cl) & Sensitivity (\%) & Specificity (\%) & $p$ \\
\hline $\operatorname{MRPD}\left(\mathrm{cmH}_{2} \mathrm{O} \cdot \mathrm{ms}^{-1}\right)$ & 0.735 (0.570 to 0.863$)$ & $-0.300(-0.535 .7$ to $-0.232 .1)$ & 76.92 & 73.98 & $<0.001$ \\
\hline 1/2 RT (ms) & 0.506 (0.341 to 0.669$)$ & 160 (106 to 206) & 76.92 & 42.31 & 0.853 \\
\hline $\mathrm{CT}(\mathrm{ms})$ & 0.648 (0.479 to 0.794$)$ & 250 (198 to 282 ) & 76.92 & 65.38 & 0.118 \\
\hline SNIP (\%pred) & 0.618 (0.449 to 0.769 ) & 46.33 (17.4 to 67.0$)$ & 76.92 & 53.85 & 0.194 \\
\hline FVC (\%pred) & 0.749 (0.584 to 0.873$)$ & 41.7 (35.3 to 106.3 ) & 53.85 & 92.31 & 0.009 \\
\hline
\end{tabular}

ALSFRS- $R$, amyotrophic lateral sclerosis functional rating scale-revised; AUC, area under curve; $C l$, confidence interval; MRR, maximum relaxation rate, MRPD, maximum rate of pressure development; $\tau$, tau; 1/2RT, half-relaxation time; CT, contraction time; SNIP, sniff nasal inspiratory pressure; FVC, forced vital capacity; ES, effect size; \%pred, percentage of predicted; $\mathrm{CmH}_{2} \mathrm{O}$, centimeter of water; $\mathrm{ALS}$, amyotrophic lateral sclerosis.

TABLE 5 | Receiver operating characteristic analysis between ALS subjects classified according to a decrease in the respiratory subscore (R-subscore) of the ALSFRS-R scale.

\begin{tabular}{|c|c|c|c|c|c|}
\hline \multicolumn{6}{|c|}{ ALS-R-subscore } \\
\hline & AUC $(95 \% \mathrm{Cl})$ & Optimal cutoff (95\% Cl) & Sensitivity (\%) & Specificity (\%) & $p$ \\
\hline $\operatorname{MRR}\left(\mathrm{ms}^{-1}\right)$ & 0.654 (0.485 to 0.799) & 0.0065 (0.0053 to 0.0086) & 64.29 & 72 & 0.130 \\
\hline $\operatorname{MRPD}\left(\mathrm{cmH}_{2} \mathrm{O} \cdot \mathrm{ms}^{-1}\right)$ & 0.721 (0.555 to 0.853$)$ & $-0.300(-0.500$ to -0.288$)$ & 71.43 & 72 & 0.01 \\
\hline$\tau(\mathrm{ms})$ & 0.824 (0.669 to 0.927$)$ & 89.1 (70.1 to 168$)$ & 85.71 & 72 & $<0.0001$ \\
\hline 1/2 RT (ms) & 0.720 (0.553 to 0.852$)$ & 160 (158 to 256$)$ & 92.86 & 52 & 0.01 \\
\hline $\mathrm{CT}(\mathrm{ms})$ & 0.657 (0.488 to 0.801$)$ & 232 (199 to 280) & 78.57 & 64 & 0.08 \\
\hline SNIP (\%pred) & $0.614(0.445$ to 0.765$)$ & $67(60$ to 67$)$ & 100 & 32 & 0.216 \\
\hline FVC (\%pred) & 0.700 (0.532 to 0.836$)$ & $67.5(63.7$ to 106$)$ & 85.71 & 52 & 0.03 \\
\hline
\end{tabular}

AUC, area under curve; $\mathrm{Cl}$, confidence interval; MRR, maximum relaxation rate, MRPD, maximum rate of pressure development; $\tau$, tau; $1 / 2 R T$, half-relaxation time; $C T$, contraction time; SNIP, sniff nasal inspiratory pressure; FVC, forced vital capacity; ES, effect size; \%pred, percentage of predicted; $\mathrm{cmH}_{2} \mathrm{O}$, centimeter of water; ALS, amyotrophic lateral sclerosis.

TABLE 6 | Receiver operating characteristic analysis between ALS subjects classified according to a decrease in FVC.

\begin{tabular}{|c|c|c|c|c|c|}
\hline \multicolumn{6}{|c|}{ ALS-FVC $\%$ pred } \\
\hline & AUC $(95 \% \mathrm{Cl})$ & Optimal Cutoff $(95 \% \mathrm{Cl})$ & Sensitivity (\%) & Specificity (\%) & $p$ \\
\hline $\operatorname{MRR}\left(\mathrm{ms}^{-1}\right)$ & 0.572 (0.485 to 0.799) & 0.0086 (0.0053 to 0.0086) & 95.83 & 26.67 & 0.467 \\
\hline $\operatorname{MRPD}\left(\mathrm{cmH}_{2} \mathrm{O} \cdot \mathrm{ms}^{-1}\right)$ & 0.781 (0.555 to 0.853$)$ & $-0.460(-0.500$ to -0.288$)$ & 95.83 & 53.33 & $<0.001$ \\
\hline$\tau(\mathrm{ms})$ & 0.794 (0.669 to 0.927$)$ & 73.1 (70.1 to 168$)$ & 79.17 & 73.33 & 0.0001 \\
\hline 1/2 RT (ms) & 0.632 (0.553 to 0.852$)$ & 174 (158 to 256$)$ & 62.50 & 73.33 & 0.162 \\
\hline $\mathrm{CT}(\mathrm{ms})$ & 0.536 (0.488 to 0.801$)$ & 304 (199 to 280) & 100 & 13.33 & 0.713 \\
\hline SNIP (\%pred) & $0.769(0.445$ to 0.765$)$ & 46.7 (60 to 67) & 79.17 & 73.33 & 0.002 \\
\hline
\end{tabular}

AUC, area under curve; Cl, confidence interval; MRR, maximum relaxation rate, MRPD, maximum rate of pressure development; $\tau$, tau; $1 / 2 R T$, half-relaxation time; CT, contraction time; SNIP, sniff nasal inspiratory pressure; FVC, forced vital capacity; ES, effect size; \%pred, percentage of predicted; $\mathrm{cmH}_{2} \mathrm{O}$, centimeter of water; ALS, amyotrophic lateral sclerosis. 

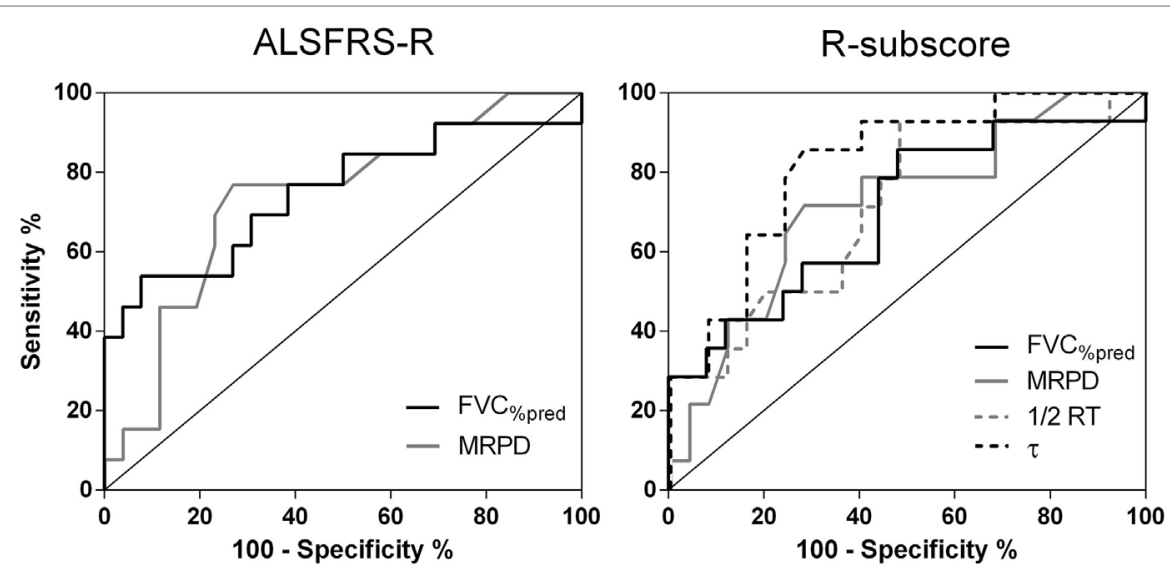

Forced Vital Capacity ${ }_{(\% p r e d)}$

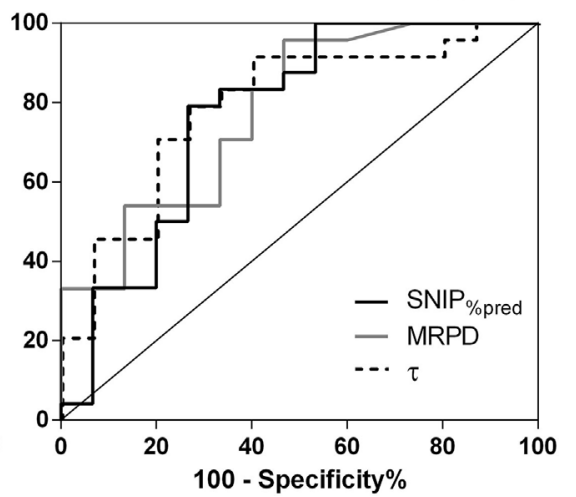

FIGURE 3 | Receiver operating characteristic curves of sniff nasal inspiratory pressure (SNIP) parameters that showed to be statistically significant in middle stage ALS subjects according to a decline in the percentage of predicted forced vital capacity (FVC) and in the ALSFRS-R score and R-subscore.

effect. Because of this, we chose to subdivide the ALS subjects into those with ALSFRS-R of $\leq 30$ and $>30$ points (decline of 15 points-37.5\%) and with the R-subscore of $\leq 9$ and $>9$ points (decline of 3 points-25\%). Moreover, as changes in $\mathrm{FVC}_{\% \text { pred }}$ over time strongly predicts respiratory muscle weakness, ventilatory failure and death in $\operatorname{ALS}(2,38,39)$, subjects were also subdivided into $\leq 70$ and $>70 \%$ FVC $_{\% \text { pred }}$ subgroups.

The value of the $\mathrm{FVC}_{\%}$ pred was the only parameter that differed between middle stage ALS subjects of both ALSFRS-R and R-subscore subgroups, possibly because the decrease of this parameter is not related only to respiratory musculature function $(36,60)$. On the other hand, when subdividing according to the R-subscore, $1 / 2 \mathrm{RT}$, and $\tau$ values were significantly different between middle stage ALS subjects which demonstrate that these diaphragmatic properties $(32,61)$ are probably related to the respiratory function assessed by this subdomain. Presumably, the most interesting fact is that SNIP\%pred, a parameter that reflects the diaphragmatic strength and predicts survival in ALS (62), only differ between those middle stage ALS subjects classified according to the decline in $\mathrm{FVC}_{\% \text { pred. }}$ Although data were collected in a single point of the disease stage, it is known that the peak pressure of sniff test declines less when compared to the decline in ALSFRS-R (8) leading us to consider that $\mathrm{SNIP}_{\% \text { pred }}$ is not a parameter that is sensitive to small changes in the ALSFRS-R and R-subscore. Regarding MRPD and $\tau$, the results were not surprising since the first is related to respiratory muscle function (11) as well as related to neural adaptations $(19,20,63)$ and the second increases well before diaphragmatic pressure is reduced during respiratory muscle weakness or fatigue $(17,34)$.

The results of the ROC curves show that all parameters extracted from the sniff curve can highly discriminate middle stage ALS from healthy subjects. When taking into account the functional decline of ALS subjects, only MRPD and FVC\%pred could predict a fall in $37.5 \%$ of the ALSFRS-R score. Among all parameters, $\tau$ provides the highest discriminative power in predicting a decline of $25 \%$ in the R-subscore. This power was even higher than $\mathrm{FVC}_{\% \text { pred, }}$ possibly because the R-subscore is less sensitive in predicting a fall in $\mathrm{FVC}_{\% \text { pred }}$ (57). Moreover, as ALS patients with $\mathrm{R}$-subscore $<11$ points are considered with relevant symptoms of respiratory distress as well as at risk of respiratory insufficiency $(57,58)$ and peak pressure of sniff test could not detect a fall in the ALSFRS-R and R-subscore, we believe that the SNIP\%pred might not be a parameter as reliable as some parameters extracted from the SNIP curve (i.e., $\tau$, MRPD, and $1 / 2 \mathrm{RT}$ ) or $\mathrm{FVC}_{\% \text { pred }}$ in detecting a clinically meaningful decline in functional and respiratory status. The SNIP\%pred was reliable in detecting respiratory muscle weakness $(39,60)$ in our middle stage ALS subjects only when considering the $\mathrm{FVC}_{\% \text { pred }}$ classification; nevertheless, MRPD and $\tau$ parameters were still more sensitive than $\mathrm{SNIP}_{\% \text { pred. }}$.

It is unlikely that the results found are investigator related since all measurements were performed by the same experienced respiratory physiotherapist. We believe that four are the main limitations of the study. First, even with a calculated statistical power of $1-\beta=0.99$, our ALS cohort may be limited in terms of sample size; second, the mean age of ALS included is lower than those of the main epidemiological studies $(64,65)$; third, we included only ALS patients at middle stage of the disease; and fourth, not all subjects could be paired by the same exact age and BMI. Further studies including patients with other motor neuron disorders are needed. Finally, ongoing longitudinal studies are already investigating these parameters during varying levels of disease progression in order to identify differences between patients with and without the need for non-invasive ventilation as well as the optimal parameter and its cutoff point able to predict an appropriate timing for the initiation of non-invasive ventilation.

In terms of clinical applicability, the calculation of the SNIP curve parameters can be easily performed and give more information about the state of the respiratory muscles, thus possibly allowing an early detection of weakness or fatigue before respiratory failure is reached $(35,53)$ as well as early implementation of new therapeutic interventions before the beginning of the peak pressure decay of the SNIP curve $(17,31,51)$. 


\section{CONCLUSION}

The contractile properties and relaxation rates of the diaphragm are altered in middle stage spinal onset ALS when compared with healthy subjects. When assessed through the nasal inspiratory sniff test, these parameters are able to discriminate between those ALS subjects with early decline in inspiratory muscle function and those who not. In addition, despite the limitations of our cohort and especially the lack of longitudinal data, we suggest that $\tau$, MRPD, and 1/2RT parameters may be able to predict ALS patients at risk of ventilatory failure before the beginning of the fall in peak pressure of sniff test.

\section{ETHICS STATEMENT}

All procedures performed in studies involving human participants were in accordance with the recommendations of the National Health Council in Brazil according to the resolution 466/12. The protocol was approved by the Research Ethics Committee of the Hospital Universitário Onofre Lopes under number $1.344 .512 / 2015$. All subjects gave written informed consent in accordance with the Declaration of Helsinki.

\section{REFERENCES}

1. Haverkamp LJ, Appel V, Appel SH. Natural history of amyotrophic lateral sclerosis in a database population. Validation of a scoring system and a model for survival prediction. Brain (1995) 118(Pt 3):707-19. doi:10.1093/ brain/118.3.707

2. Czaplinski A, Yen AA, Simpson EP, Appel SH. Predictability of disease progression in amyotrophic lateral sclerosis. Muscle Nerve (2006) 34(6):702-8. doi:10.1002/mus.20658

3. de Carvalho M, Matias T, Coelho F, Evangelista T, Pinto A, Luis ML. Motor neuron disease presenting with respiratory failure. JNeurol Sci (1996) 139(Suppl):117-22. doi:10.1016/0022-510X(96)00089-5

4. Chen R, Grand'Maison F, Strong MJ, Ramsay DA, Bolton CF. Motor neuron disease presenting as acute respiratory failure: a clinical and pathological study. J Neurol Neurosurg Psychiatry (1996) 60(4):455-8. doi:10.1136/jnnp. 60.4 .455

5. Guedes K, Pereira C, Pavan K, Valerio BC. Cross-cultural adaptation and validation of als functional rating scale-revised in Portuguese language. Arq Neuropsiquiatr (2010) 68(1):44-7. doi:10.1590/S0004-282X2010000100010

6. Kaufmann P, Levy G, Thompson JL, Delbene ML, Battista V, Gordon PH, et al. The ALSFRSr predicts survival time in an ALS clinic population. Neurology (2005) 64(1):38-43. doi:10.1212/01.WNL.0000148648.38313.64

7. Kollewe K, Mauss U, Krampfl K, Petri S, Dengler R, Mohammadi B. ALSFRS-R score and its ratio: a useful predictor for ALS-progression. J Neurol Sci (2008) 275(1-2):69-73. doi:10.1016/j.jns.2008.07.016

8. Bauer M, Czell D, Hartmann S, Goldman B, Muller D, Weber M. Limitations of sniff nasal pressure as an outcome measurement in amyotrophic lateral sclerosis patients in a clinical trial. Respiration (2012) 84(4):306-11. doi:10.1159/ 000339415

9. Magnus T, Beck M, Giess R, Puls I, Naumann M, Toyka KV. Disease progression in amyotrophic lateral sclerosis: predictors of survival. Muscle Nerve (2002) 25(5):709-14. doi:10.1002/mus.10090

10. Polkey MI, Lyall RA, Yang K, Johnson E, Leigh PN, Moxham J. Respiratory muscle strength as a predictive biomarker for survival in amyotrophic lateral sclerosis. Am J Respir Crit Care Med (2017) 195(1):86-95. doi:10.1164/ rccm.201604-0848OC

11. American Thoracic Society/European Respiratory Society. ATS/ERS statement on respiratory muscle testing. Am J Respir Crit Care Med (2002) 166(4): 518-624. doi:10.1164/rccm.166.4.518

\section{AUTHOR CONTRIBUTIONS}

AS, GF, and VR designed the study. GF, VR, and AA supervised the study. AS, LM, and MD-J collected the data and performed clinical assessment. AS, GF, FP, VR, and AA analyzed/interpreted the data. AS wrote the manuscript, and GF, LM, FP, MD-J, VR, and $\mathrm{AA}$ revised the manuscript.

\section{ACKNOWLEDGMENTS}

The study was funded by Coordenação de Aperfeiçoamento de Pessoal de Nível Superior (CAPES) - PGCI 23.038.007514/ 2014-78 and 054/2014. GF is Fellow from Conselho Nacional de Desenvolvimento Científico e Tecnológico (CNPq) number: 307353/2015-0 and VR is Fellow from CNPq number: 310091/2015-2.

\section{SUPPLEMENTARY MATERIAL}

The Supplementary Material for this article can be found online at https://www.frontiersin.org/articles/10.3389/fneur.2018.00306/ full\#supplementary-material.

12. Miller JM, Moxham J, Green M. The maximal sniff in the assessment of diaphragm function in man. Clin Sci (1985) 69(1):91-6. doi:10.1042/cs0690091

13. Laroche CM, Mier AK, Moxham J, Green M. The value of sniff esophageal pressures in the assessment of global inspiratory muscle strength. Am Rev Respir Dis (1988) 138(3):598-603. doi:10.1164/ajrccm/138.3.598

14. Schiffman PL, Belsh JM. Effect of inspiratory resistance and theophylline on respiratory muscle strength in patients with amyotrophic lateral sclerosis. Am Rev Respir Dis (1989) 139(6):1418-23. doi:10.1164/ajrccm/139. 6.1418

15. Troyer AD, Estenne M. The respiratory system in neuromuscular disorders. In: Roussos CH, editor. The Thorax. New York: Marcel Dekker (1995), p. 2177-2206

16. Koulouris N, Vianna LG, Mulvey DA, Green M, Moxham J. Maximal relaxation rates of esophageal, nose, and mouth pressures during a sniff reflect inspiratory muscle fatigue. Am Rev Respir Dis (1989) 139(5):1213-7. doi:10.1164/ajrccm/139.5.1213

17. Esau SA, Bellemare F, Grassino A, Permutt S, Roussos C, Pardy RL. Changes in relaxation rate with diaphragmatic fatigue in humans. J Appl Physiol (1983) 54(5):1353-60. doi:10.1152/jappl.1983.54.5.1353

18. Mador MJ, Kufel TJ. Effect of inspiratory muscle fatigue on inspiratory muscle relaxation rates in healthy subjects. Chest (1992) 102(6):1767-73. doi:10.1378/ chest.102.6.1767

19. Matthews AW, Howell JB. The rate of isometric inspiratory pressure development as a measure of responsiveness to carbon dioxide in man. Clin Sci Mol Med (1975) 49(1):57-68.

20. Tzelepis GE, Kasas V, McCool FD. Inspiratory muscle adaptations following pressure or flow training in humans. Eur J Appl Physiol Occup Physiol (1999) 79(6):467-71. doi:10.1007/s004210050538

21. Romer LM, McConnell AK. Inter-test reliability for non-invasive measures of respiratory muscle function in healthy humans. Eur J Appl Physiol (2004) 91(2-3):167-76. doi:10.1007/s00421-003-0984-2

22. Kyroussis D, Mills G, Hamnegard CH, Wragg S, Road J, Green M, et al. Inspiratory muscle relaxation rate assessed from sniff nasal pressure. Thorax (1994) 49(11):1127-33. doi:10.1136/thx.49.11.1127

23. Levy RD, Esau SA, Bye PT, Pardy RL. Relaxation rate of mouth pressure with sniffs at rest and with inspiratory muscle fatigue. Am Rev Respir Dis (1984) 130(1):38-41.

24. Benicio K, Dias FA, Gualdi LP, Aliverti A, Resqueti VR, Fregonezi GA. Effects of diaphragmatic control on the assessment of sniff nasal inspiratory 
pressure and maximum relaxation rate. Braz J Phys Ther (2016) 20(1):96-103. doi:10.1590/bjpt-rbf.2014.0101

25. Brooks BR, Miller RG, Swash M, Munsat TL; World Federation of Neurology Research Group on Motor Neuron Diseases. El Escorial revisited: revised criteria for the diagnosis of amyotrophic lateral sclerosis. Amyotroph Lateral Scler Other Motor Neuron Disord (2000) 1(5):293-9. doi:10.1080/ 146608200300079536

26. Pereira CAC, Neder JA. Sociedade Brasileira de Pneumologia e Tisiologia SBPT. Diretrizes para testes de função pulmonar. J Bras Pneumol (2002) 29(3):207-21.

27. Heritier F, Rahm F, Pasche P, Fitting JW. Sniff nasal inspiratory pressure. A noninvasive assessment of inspiratory muscle strength. Am J Respir Crit Care Med (1994) 150(6 Pt 1):1678-83. doi:10.1164/ajrccm.150.6.7952632

28. Neder JA, Andreoni S, Lerario MC, Nery LE. Reference values for lung function tests: II. Maximal respiratory pressures and voluntary ventilation. Braz J Med Biol Res (1999) 32:719-27. doi:10.1590/S0100-879X1999000600007

29. Araujo PR, ResquetiVR, Nascimento Junior J, CarvalhoLdeA,CavalcantiAG, Silva VC, et al. Reference values for sniff nasal inspiratory pressure in healthy subjects in Brazil: a multicenter study. J Bras Pneumol (2012) 38 (6):700-7. doi:10.1590/\$1806-37132012000600004

30. Smith J, Bellemare F. Effect of lung volume on in vivo contraction characteristics of human diaphragm. J Appl Physiol (1987) 62(5):1893-900. doi:10.1152/ jappl.1987.62.5.1893

31. Goldstone JC, Green M, Moxham J. Maximum relaxation rate of the diaphragm during weaning from mechanical ventilation. Thorax (1994) 49(1): 54-60. doi:10.1136/thx.49.1.54

32. Bellemare F, Bigland-Ritchie B, Woods JJ. Contractile properties of the human diaphragm in vivo. J Appl Physiol (1986) 61(3):1153-61. doi:10.1152/jappl. 1986.61.3.1153

33. Romer LM, McConnell AK. Specificity and reversibility of inspiratory muscle training. Med Sci Sports Exerc (2003) 35(2):237-44. doi:10.1249/01. MSS.0000048642.58419.1E

34. Esau SA, Bye PT, Pardy RL. Changes in rate of relaxation of sniffs with diaphragmatic fatigue in humans. J Appl Physiol (1983) 55(3):731-5. doi:10.1152/ jappl.1983.55.3.731

35. Wilcox PG, Eisen A, Wiggs BJ, Pardy RL. Diaphragmatic relaxation rate after voluntary contractions and uni- and bilateral phrenic stimulation. J Appl Physiol (1988) 65(2):675-82. doi:10.1152/jappl.1988.65.2.675

36. Cedarbaum JM, Stambler N, Malta E, Fuller C, Hilt D, Thurmond B, et al. The ALSFRS-R: a revised ALS functional rating scale that incorporates assessments of respiratory function. J Neurol Sci (1999) 169(1):13-21. doi:10.1016/ S0022-510X(99)00210-5

37. Roche JC, Rojas-Garcia R, Scott KM, Scotton W, Ellis CE, Burman R, et al. A proposed staging system for amyotrophic lateral sclerosis. Brain (2012) 135(Pt 3):847-52. doi:10.1093/brain/awr351

38. Pinto S, Carvalho M. Breathing new life into treatment advances for respiratory failure in amyotrophic lateral sclerosis patients. Neurodegener Dis Manag (2014) 4(1):83-102. doi:10.2217/nmt.13.74

39. Andrews JA, Meng L, Kulke SF, Rudnicki SA, Wolff AA, Bozik ME, et al. Association between decline in slow vital capacity and respiratory insufficiency, use of assisted ventilation, tracheostomy, or death in patients with amyotrophic lateral sclerosis. JAMA Neurol (2018) 75(1):58-64. doi:10.1001/ jamaneurol.2017.3339

40. Gordon PH, Cheng B, Montes J, Doorish C, Albert SM, Mitsumoto H. Outcome measures for early phase clinical trials. Amyotroph Lateral Scler (2007) 8(5):270-3. doi:10.1080/17482960701547958

41. Castrillo-Viguera C, Grasso DL, Simpson E, Shefner J, Cudkowicz ME. Clinical significance in the change of decline in ALSFRS-R. Amyotroph Lateral Scler (2010) 11(1-2):178-80. doi:10.3109/17482960903093710

42. Cohen J. Statistical Power Analysis for the Behavioral Sciences. 2nd ed. Hillsdale, New Jersey: Lawrence Erlbaum Associates, Inc (1988).

43. Fritz CO, Morris PE, Richler JJ. Effect size estimates: current use, calculations, and interpretation. J Exp Psychol Gen (2012) 141(1):2-18. doi:10.1037/ a0024338

44. Tomczak M, Tomczak E. The need to report effect size estimates revisited. An overview of some recommended measures of effect size. Trends Sport Sci (2014) 1(21):19-25.

45. Youden WJ. Index for rating diagnostic tests. Cancer (1950) 3(1):32-5. doi:10.1002/1097-0142(1950)3:1<32::AID-CNCR2820030106>3.0.CO;2-3
46. Capozzo R, Quaranta VN, Pellegrini F, Fontana A, Copetti M, Carratu P, et al. Sniff nasal inspiratory pressure as a prognostic factor of tracheostomy or death in amyotrophic lateral sclerosis. J Neurol (2015) 262(3):593-603. doi:10.1007/s00415-014-7613-3

47. Garcia-Rio F, Mediano O, Pino JM, Lores V, Fernandez I, Alvarez-Sala JL, et al. Noninvasive measurement of the maximum relaxation rate of inspiratory muscles in patients with neuromuscular disorders. Respiration (2006) 73(4):474-80. doi:10.1159/000091804

48. Mulvey DA, Koulouris NG, Elliott MW, Moxham J, Green M. Maximal relaxation rate of inspiratory muscle can be effort-dependent and reflect the activation of fast-twitch fibers. Am Rev Respir Dis (1991) 144(4):803-6. doi:10.1164/ajrccm/144.4.803

49. Evangelista MA, Dias FAL, Dourado Junior MET, do Nascimento GC, Sarmento A, Gualdi LP, et al. Noninvasive assessment of respiratory muscle strength and activity in myotonic dystrophy. PLoS One (2017) 12(6):e0177318. doi:10.1371/journal.pone.0177318

50. Coirault C, Chemla D, Lecarpentier Y. Relaxation of diaphragm muscle. J Appl Physiol (1999) 87(4):1243-52. doi:10.1152/jappl.1999.87.4.1243

51. Polkey MI, Kyroussis D, Mills GH, Hamnegard CH, Keilty SE, Green M, et al. Inspiratory pressure support reduces slowing of inspiratory muscle relaxation rate during exhaustive treadmill walking in severe COPD. Am J Respir Crit Care Med (1996) 154(4 Pt 1):1146-50. doi:10.1164/ajrccm. 154.4.8887619

52. Bigland-Ritchie B, Johansson R, Lippold OC, Woods JJ. Contractile speed and EMG changes during fatigue of sustained maximal voluntary contractions. J Neurophysiol (1983) 50(1):313-24. doi:10.1152/jn.1983.50.1.313

53. Grassino A, Macklem PT. Respiratory muscle fatigue and ventilatory failure. Annu Rev Med (1984) 35:625-47. doi:10.1146/annurev.me.35.020184. 003205

54. Dawson MJ, Gadian DG, Wilkie DR. Mechanical relaxation rate and metabolism studied in fatiguing muscle by phosphorus nuclear magnetic resonance. J Physiol (1980) 299:465-84. doi:10.1113/jphysiol.1980. sp013137

55. Dassios T, Kaditis A, Katelari A, Chrousos G, Doudounakis S, Dimitriou G. Time constant of inspiratory muscle relaxation in cystic fibrosis. Pediatr Res (2015) 77(4):541-5. doi:10.1038/pr.2015.2

56. Dassios TG, Doudounakis S, Dimitriou G. Maximum rate of pressure development and maximal relaxation rate of respiratory muscles in patients with cystic fibrosis. Respir Care (2013) 58(3):474-81. doi:10.4187/respcare. 01930

57. Pinto S, Geraldes R, Vaz N, Pinto A, de Carvalho M. Changes of the phrenic nerve motor response in amyotrophic lateral sclerosis: longitudinal study. Clin Neurophysiol (2009) 120(12):2082-5. doi:10.1016/j.clinph.2009. 08.025

58. Park JS, Park D. The terminal latency of the phrenic nerve correlates with respiratory symptoms in amyotrophic lateral sclerosis. Clin Neurophysiol (2017) 128(9):1625-8. doi:10.1016/j.clinph.2017.06.039

59. Kwon S, Min JH, Cho HJ, Joo BE, Cho EB, Seok JM, et al. Usefulness of phrenic latency and forced vital capacity in patients with ALS with latent respiratory dysfunction. Clin Neurophysiol (2015) 126(7):1421-6. doi:10.1016/j. clinph.2014.10.006

60. Pinto S, de Carvalho M. Correlation between forced vital capacity and slow vital capacity for the assessment of respiratory involvement in amyotrophic lateral sclerosis: a prospective study. Amyotroph Lateral Scler Frontotemporal Degener (2017) 18(1-2):86-91. doi:10.1080/21678421. 2016.1249486

61. Rochester DF. The diaphragm: contractile properties and fatigue. J Clin Invest (1985) 75(5):1397-402. doi:10.1172/JCI111841

62. Morgan RK, McNally S, Alexander M, Conroy R, Hardiman O, Costello RW. Use of sniff nasal-inspiratory force to predict survival in amyotrophic lateral sclerosis. Am J Respir Crit Care Med (2005) 171(3):269-74. doi:10.1164/ rccm.200403-314OC

63. Behm DG, Sale DG. Intended rather than actual movement velocity determines velocity-specific training response. J Appl Physiol (1993) 74(1):359-68. doi:10.1152/jappl.1993.74.1.359

64. Chio A, Logroscino G, Traynor BJ, Collins J, Simeone JC, Goldstein LA, et al. Global epidemiology of amyotrophic lateral sclerosis: a systematic review of the published literature. Neuroepidemiology (2013) 41(2):118-30. doi:10.1159/000351153 
65. Marin B, Boumediene F, Logroscino G, Couratier P, Babron MC, Leutenegger AL, et al. Variation in worldwide incidence of amyotrophic lateral sclerosis: a meta-analysis. Int J Epidemiol (2017) 46(1):57-74. doi:10.1093/ije/dyw061

Conflict of Interest Statement: The authors declare that the research was conducted in the absence of any commercial or financial relationships that could be construed as a potential conflict of interest.
Copyright (c) 2018 Sarmento, Aliverti, Marques, Pennati, Dourado-Júnior, Fregonezi and Resqueti. This is an open-access article distributed under the terms of the Creative Commons Attribution License (CC BY). The use, distribution or reproduction in other forums is permitted, provided the original author(s) and the copyright owner are credited and that the original publication in this journal is cited, in accordance with accepted academic practice. No use, distribution or reproduction is permitted which does not comply with these terms. 